\title{
Design and Testing of a Meso-Scale Pneumatic Actuated Electrical Power Generator
}

\author{
A.T. Al-Halhouli ${ }^{\text {a,*** }}$, M. Abu Rumman ${ }^{\text {b }}$, M. Zgoul ${ }^{\mathrm{b}}$ \\ ${ }^{a}$ Mechatronics Engineering Department, German Jordanian University, Mushaqar, Jordan \\ ${ }^{b}$ Mechanical Engineering Department, University of Jordan, Amman 11942, Jordan
}

\begin{abstract}
This work presents experimental study on pneumatic actuated meso-scale permanent magnet power generator. It aims at generating electrical power by spinning a rotor carrying permanent magnets at low rotational speeds to induce current in conducting windings set in a stator in close proximity below the magnets. A number of miniaturized generators were manufactured and tested under different parameters, including: number of winding turns, conducting wire size, number of inserted permanent magnets into the rotor, and spinning speed. In addition, the effect of inserting back-iron to the stator onto output power generation was investigated. The generator was tested experimentally and showed that it can generate milliwatt to watt level power. These investigations have demonstrated the feasibility and scalability of magnetic devices for power generating applications. The generator delivered a power of $1.45 \mathrm{~W}$ at resistive load of 30 and spinning speed of $6000 \mathrm{rpm}$.
\end{abstract}

Keywords: electromagnetic, fluid power, electrical generator

\section{Introduction}

The last few years have experienced a growing trend in the miniaturization of mechanical and electromechanical engineering devices. This follows the revolution initiated by the areas of microelectronics, biomechanics, and micro-fabrication. High precision fabrication of devices in the centimeter scale range were made using micro-fabrication techniques such as electrodischarge machining (EDM), laser beam machining (LBM) or focused ion beam machining (FIBM). Devices in the millimeter scale range were fabricated using Micro-Electro-Mechanical Systems (MEMS). Materials are similar to those used in the integrated circuit /microchip industry. Although initially the micro-devices produced using EDM, LBM or FIBM were primarily

* Corresponding author. Tel.: +962- 6-429 4511

e-mail: alaaldeen.alhalhoul@gjuedu.jo

(C) 2015 International Association for Sharing Knowledge and Sustainability

DOI: $10.5383 /$ ijtee. 10.01 .010 related to biomedicine, and those fabricated using MEMS were sensors and actuators, recently other more complex devices such as pumps, motors, and valves were developed [1-3].

On the other hand, a great interest in producing miniaturized mechanical devices with high energy (i.e., small size, low weight, and long duration) was promising and opens exciting new opportunities for miniaturized power generation, especially in the field of mesoscalepower generation. Typical portable consumer electronics suffer from short operation cycles between charges or replacement, and their overall weight consists largely of battery weight. Similarly, other more advanced MEMS based devices depend on battery systems that occupy significant fractions of both mass and volume of the entire device. This imposed the challenge of reducing system weight, increasing operational lifetimes, and reducing unit cost. 
Accordingly, many attempts were conducted to extract an effective method to obtain the best design of miniaturized motors/generators with the maximum power generation. A generator that is capable to extract up to $117 \mu \mathrm{W}$ of power from body motion, walking, employing a non-resonant rotational mechanism was recently tested [4]. The proposed planar generator is composed of a rotor having multiple $\mathrm{NdFeB}$ permanent magnet pole-pairs with an eccentric proof mass. The stator has a multi-stacked gear shaped planar coil. A change on the magnetic flux induced a voltage in the coil when the rotor moves because of body movement. Another attempt used a miniature compressed air electrical power system that comprises of an inward-flow radial turbine and a permanent magnet generator [5]. The system has a total volume of $36.8 \mathrm{~cm}^{3}$, which leads to a power density of $4 \mathrm{~W} / \mathrm{cm}^{3}$. The work based on radial turbine with a rated rotational speed of $490000 \mathrm{rpm}$ and electric power output of $150 \mathrm{~W}$. Measurement of the compressed air to electrical power system with maximum rotational speed of over $600000 \mathrm{rpm}$, revealed a maximum electrical power output of $170 \mathrm{~W}$, a maximum torque of $5.2 \mathrm{mN}$.m and a turbine efficiency of $52 \%$.

An in-plane rotary electromagnetic micro-generator, which consists mainly of a multilayer planar copper $(\mathrm{Cu})$ micro-coil and a multipolar hard magnet made of $\mathrm{NdFeB}$ was developed. The whole volume of the system was approximately $5 \times 5 \times 2 \mathrm{~mm}^{3}$. The study focused on the design and manufacturing required to obtain a high power generation output, and developed an analytical model to predict the power output for different designs of micro generators. The geometric pattern design of the $\mathrm{Cu}$ planar micro coil is manufactured using the filament winding method. Both the line width and spacing of the micro coil are $30 \mu \mathrm{m}$. A multipolar hard NeodymiumIron-Boron (NdFeB) magnet was molded, sintered, and magnetized to produce an external magnetic field with an anisotropic residual induction $(\mathrm{Br})$ of 1.44 tesla. The theoretical model was evaluated and compared with experimental results. It showed a good agreement with the experimental results with induced electromotive force (EMF) of $111.2 \mathrm{mV}$ and a maximum power output of $0.412 \mathrm{~mW}$ at a frequency of $149.3 \mathrm{~Hz}$ [6].

Another miniature gas turbine was developed [7] to generate electrical energy from fuel. This system consists of a compressor, combustion chamber, turbine and generator. The turbine is a single-stage axial impulse turbine with a rotor diameter of $10 \mathrm{~mm}$, made of stainless steel using die-sinking electro-discharge machining. It has been tested with compressed air to speeds up to $160000 \mathrm{rpm}$ and generates a maximum mechanical power of $28 \mathrm{~W}$ with an efficiency of $18.4 \%$. When coupled to a small generator, it generates $16 \mathrm{~W}$ of electrical power, which corresponds to efficiency for the total system of $10.5 \%$. An improved turbine has been tested at temperatures up to $360{ }^{\circ} \mathrm{C}$ and generates up to $44 \mathrm{~W}$ of electrical energy with a total efficiency of $16 \%$. For this study, because of its added advantages such as: availability, environmental-friendly, low cost and less components, air was considered as the working fluid for the proposed power generation system.

The aim of the present study is to design and experimentally investigate a meso-scale electrical power generation system operating with compressed air (pneumatic based power generator). This will improve our understanding of the operation and performance of the miniaturized pneumatic generators for electric power generation.

\section{Generator Operation and Design}

The pneumatic power generator prototype is an axialflux permanent-magnet device that consists of a Teflon rotor disk, a stator carrying the conducting coils, a turbine and a connecting shaft (Fig. 1).

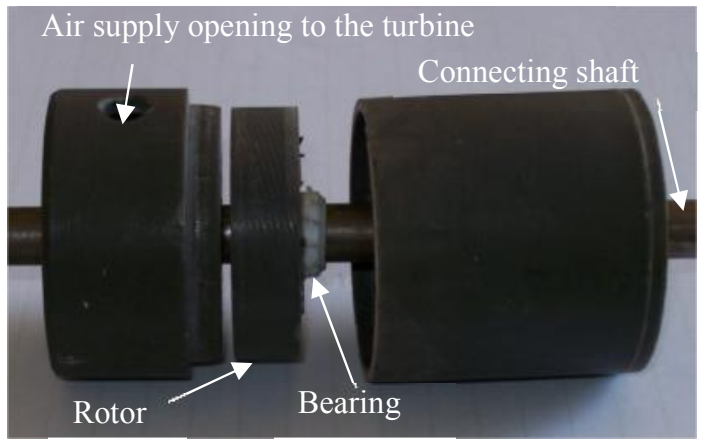

Figure 1 Photo of the pneumatic generator components.

To run the device, compressed air was passed through the air supply port to rotate the turbine blades. The turbine impeller was connected to the rotor which will consequently rotates approximately at the same speed in close proximity above the stator windings to generate electrical power.
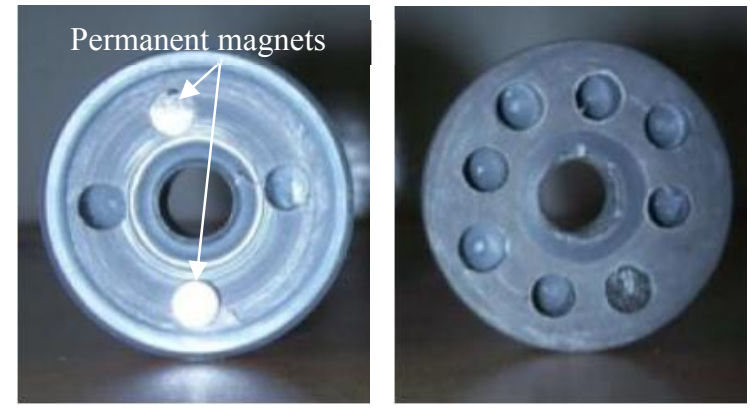

Figure 2 Teflon rotor designs: 4 PMs cavities with 2 PMs placed into the rotor face (left), 8 PMs cavities at rotor surface (right).

In operation, a spinning rotor, with alternating magnetic poles, generates a time varying magnetic field, which induces $\mathrm{AC}$ voltages in the stator windings. When the winding terminals are connected to an external load, the device generates electrical power. A rotor design of $40 \mathrm{~mm}$ outer diameters was manufactured in Teflon and tested. The manufacturing process was accomplished with the conventional lathe and $\mathrm{CNC}$ machining. The 
magnets locations were alternatively selected to be distributed evenly on the rotor surface (Fig. 2), where disks of different number of cavities for permanent magnets (PMs) were drilled. This allows the investigation of the influence of the number of distributed magnets on the output power. The $\mathrm{NdFeB}$ PMs were glued into the cavities (Fig.2, left). The maximum rotational speed of the device was 6000 RPM. For stator design purposes, which should allow for free rotation of the rotor inside the stator without any contact, even if misalignment occur, while operating the prototype. The stator prototypes were designed so that the windings will be placed in 2 and 4-slots as shown in the Fig. 3. Therefore, the factors that will be changed during experiments for the stator design are the number of the winding slots, number of winding turns and with/ without inserted back-iron.

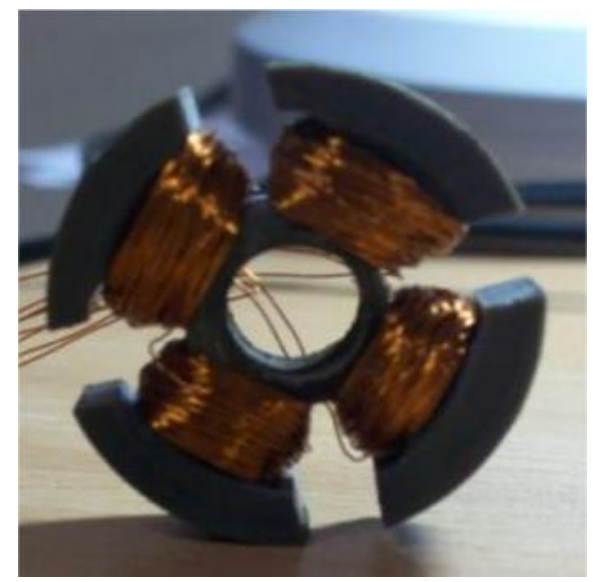

Figure 3 Stator designs with 4-slots windings

By the 4-slots design, the maximum number of turns is 500 per slot. Both ends of the phase windings are available in a connection box. The device was operated in series connection.

The winding parameters: wire size, number of turns, winding specifications are critical for device output power. On the other hand, windings ability to convert magnetic flux lines into current depends on their position relative to the flux, and on their size and composition. In order to maximize the number of flux lines that pass through the winding surface, the cross-sectional area of the windings must be positioned perpendicular to the magnetic flux lines emanating from the PMs. Both the cross-sectional area and the length of the winding also affect the winding's ability to conduct. In the process of choosing the best wire thickness, an iterative process were implemented to find the best wire thickness that can produce the higher induced current in the windings for a wire with a thickness of $1.2 \mathrm{~mm}$ down to $0.2 \mathrm{~mm}$. Experiments on output voltages showed that the best results were obtained with the of $0.2 \mathrm{~mm}$ wire.

\section{Experimental Set-up}

The testing facility consists of a pressurized air source, miniaturized generator, a mass flow sensor, phase variable resistive load, and optical shaft encoder (speed sensor) as shown in Fig. 4. The pressurized air source was produced by a fixed /floor mounted piston air compressor which can generate air up to 8 bars. The system was tested with an inlet pressure up to 1 bar where the maximum outlet electric operating point could be changed by varying the resistive load and the supply pressure. The output voltages were measured and the turbine and rotor speed was detected using the speed sensor.

The first step before recording results is running the system to make sure all set-up components are working properly. After that, the experiments were started by directing compressed air towards the turbine and controlling the generator rotational speed within the range of $0-6000 \mathrm{rpm}$. Power generation was noticed at rotational speed of $150 \mathrm{rpm}$. Tests were conducted to many prototypes and results were recorded at different number of windings, slots and number of used magnets.

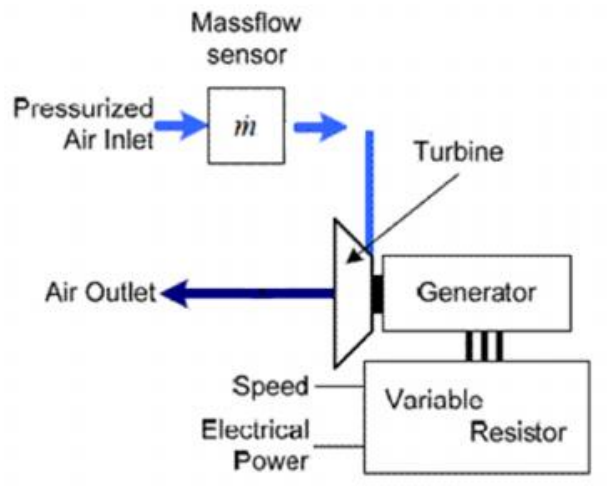

Figure 4 Experimental set-up

\section{Results}

The most interesting part of any experiment is the data, whether it validates a hypothesis or brings a new puzzle to light. Just as the miniaturized design process is an iterative one, the results from experimentation used to refine the initial design. It has been found that, at given conditions, the number of magnets that the system can operate with is at least two magnets with two stator slots and with minimum number of winding turns is 50 turns per slot as shown in Fig. 5. Results are taken with winding resistance of about $7 \Omega$ for the case of having back-iron being inserted into the stator and another without the back-iron. 


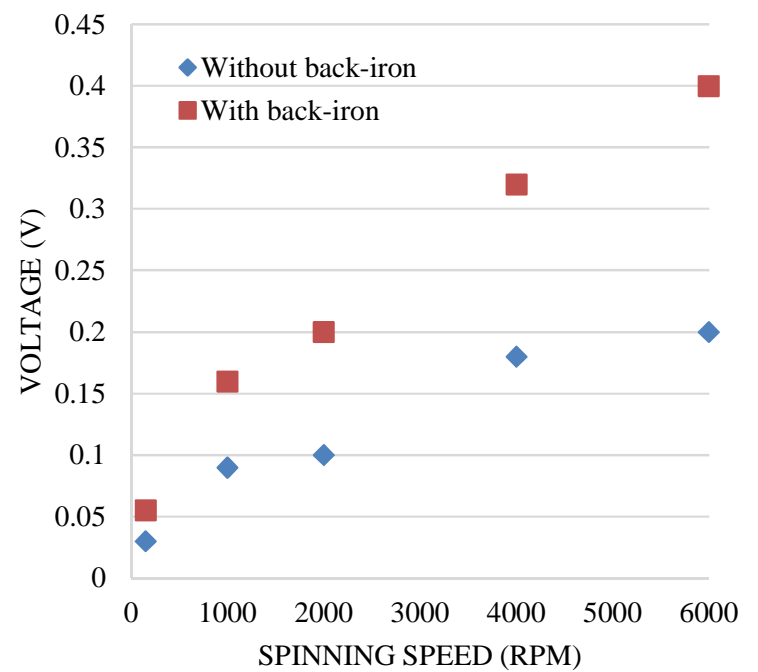

Figure 5 Experimental results of measured voltage for 50 turns, 2 slots, 2 magnets case.

Without back-iron, the system shows the minimum output voltage of about $0.03 \mathrm{~V}$ at $150 \mathrm{rpm}$ and about 0.2 $\mathrm{V}$ at $6000 \mathrm{rpm}$. Inserting the back-iron yields at a $0.06 \mathrm{~V}$ at $150 \mathrm{rpm}$.

Increasing the number of inserted magnets showed a proportional increase in the generated voltage and accordingly power (i.e., from $65 \mathrm{~mW}$ using 2 magnets to about $200 \mathrm{~mW}$ using 8 magnets) at $6000 \mathrm{rpm}$ as plotted in Fig. 6.

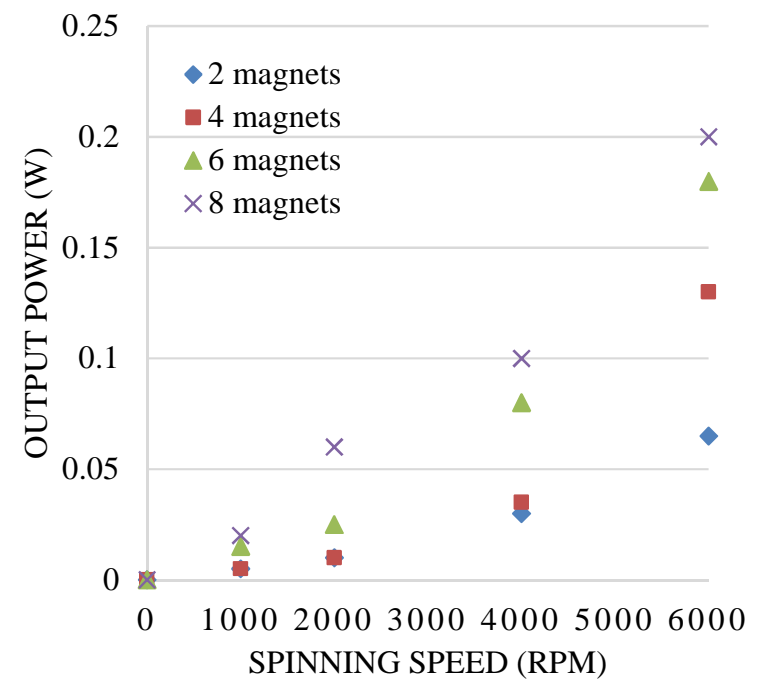

Figure 6 Experimental results of measured power output for 50 turns, 2-slots, 2 magnets case

Now, increasing the number of winding slots to 4 with the same number of turn of 50 and using 8 inserted magnets, output power of about $630 \mathrm{~mW}$ were achieved at no load condition and $6000 \mathrm{rpm}$ while $450 \mathrm{~mW}$ were reported at load condition (Fig. 7).

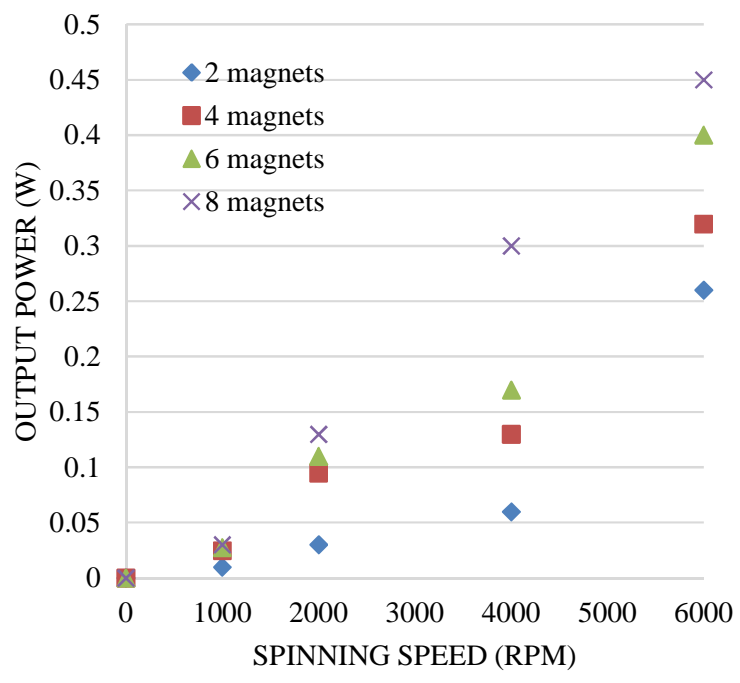

Figure 7: Experimental results of measured power output for 50 turns, 4-slots, n-magnets case.

Under the same conditions (i.e., 4-slots, 8-magnets) increasing the number of winding turns to 500 per slot yields in a maximum output voltage of about $9.7 \mathrm{~V}$ without back-iron and of about $12.4 \mathrm{~V}$ after inserting the back at $6000 \mathrm{rpm}$. Running this design with load condition $(30 \Omega)$ resulted on a maximum output power of about 1.45 watt (Fig. 8).

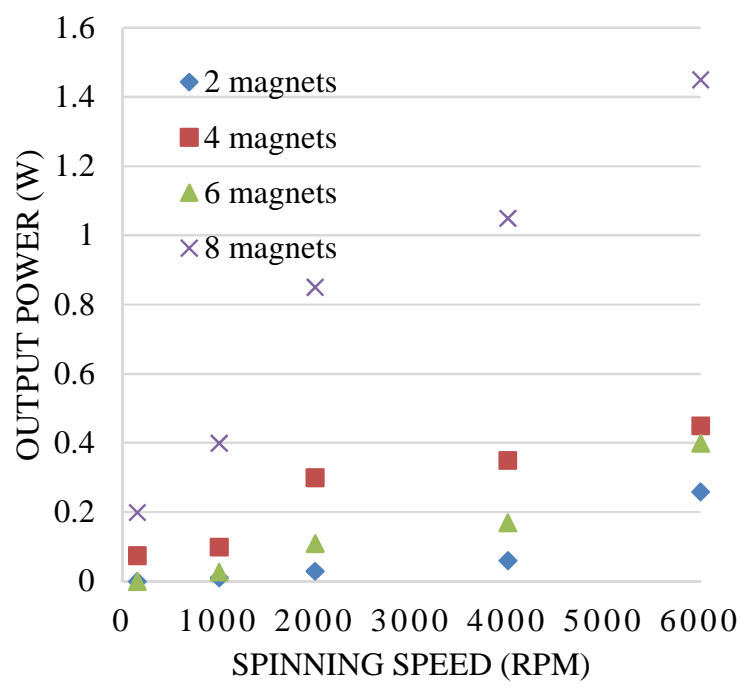

Figure 8: Power output results of measurements for 500 turns, 4-slots, n-magnets case. 


\section{Conclusions}

A pneumatic based meso-scale permanent magnet power generator was presented and investigated under different parameters: number of winding turns, conducting wire size, number of inserted permanent magnets into the rotor, spinning speed and with/ without back-iron. The generator was tested experimentally and showed that it can generate a maximum power of $1.45 \mathrm{~W}$ at resistive load of 30 and spinning speed of $6000 \mathrm{rpm}$. Increasing the number of magnets, number of turns and winding slots has a direct influence on increasing the power generator performance.

\section{References}

[1] Büttgenbach S, Balck A, Demming S, Lesche C, Michalzik M, and Al-Halhouli A T. Development of on chip devices for life science applications, International Journal of Engineering, 2009; 3 (2): 148-158.

[2] Al-Halhouli A T, Kilani M I, Waldschik A, Phataralaoha A, Büttgenbach S. Development and testing of a synchronous micropump based on electroplated coils and microfabricated polymer magnets, Journal of Micromechanics Microengineering, 2012; 22:065027.

[3] Al-Halhouli A T, Demming S, Waldschik A, and Buttgenbach S. Implementation of Synchronous Micromotor in Developing Integrated Microfluidic Systems, Micromachines, 2014, 5: 442-456.

[4] Romero E, Neuman M R, and Warrington R O, Kinetic energy harvester for body motion (WIMS) Michigan Technological University, Houghton, USA, , 2009, pp. 237-240.

[5] Krähenbühl D, Zwyssig C, Weser H and Kolar J. Mesoscale Electric Power Generation From Pressurized Gas Flow Power Electronic Systems Laboratory, J. Micromech. Microeng. 2009; 19 (9): 094009.

[6] Pan C T and WU T T. Development of rotary electromagnetic microgenerator. Journal of micromechanics and micro engineering, 2007, 17: 120-128.

[7] Jan P, Dominiek R and Fillip V. Development of an axial flux microturbine for a portable gas turbine generator. Journal of micromechanics and micro engineering, 2003; 43: 3940-3950. 